\title{
La virtut de la fortalesa als sirventesos morals de Pere March $^{1}$
}

\section{The Virtue of Fortitude in Moral Sirventes of Pere March}

\author{
LLUÍ́S RAMON I FERRER \\ Universidad Católica de Valencia \\ 1luis.ramon@ucv.es
}

Recibido: marzo de 2020. Aceptado: mayo de 2020

Resum: Aquest article és una lectura conjunta i complementària dels poemes I, II i III de Pere March. S'hi ha observat un programa ascètic basat en la virtut de la fortalesa i en les virtuts que li són annexes: magnanimitat, magnificència, paciència i perseverança. Aquestes virtuts són presentades amb exempla que il-lustren els vicis que se'ls oposen i que, sempre que ha estat possible, s'han relacionat amb el Communiloquium o Summa de Col-lacions de Joan de Gal·les, llibre present a la biblioteca del poeta.

Mots clau: Pere March, literatura catalana, poesia, edat mitjana.

\begin{abstract}
This paper is a joint and complementary reading of poems I, II and III by Pere March. An ascetic program has been observed based on the virtue of fortitude and its annexed virtues: magnanimity, magnificence, patience and perseverance. These virtues are presented, by contrast, with exampla that illustrates the vices that oppose them and that, whenever possible, have been related to the Communiloquium or Summa of Collations of John of Wales book present in the poet's library.
\end{abstract}

Keywords: Pere March, Catalan Literature, poetry, Middle Age.

\footnotetext{
${ }^{1}$ Aquest article s'inscriu al projecte MICINN, La cultura literaria medieval y moderna en la tradición manuscrita e impresa (VI), REF. FFI2017-83960-P (AEI/FEDER, UE)
} 


\section{I.- INTRODUCCIÓ}

El manuscrit Harleian 3244 de la British Library conté la Summa de virtutibus et vitiis de Guilelmus Peraldus. Aquesta obra va precedida per una il-lustració a doble pàgina amb el tipus iconogràfic del miles christianus (Ef 6,14-17) que sota el lema militia est vita hominis super terram (Jb 7,1) mostra un cavaller, al llom d'un cavall, armat d'espasa i llança i protegit amb arnés i escut. Cada una de les armes defensives i ofensives que ostenta el cavaller, així com els guarniments del cavall, simbolitzen una virtut que queda patent pel filacteri que acompanya cada cas. A l'extrem superior dret del cavaller, apareix un àngel que sosté amb la mà dreta set filacteris que contenen les benaurances (Mt 5,3-12) i amb l'esquerra posa una corona sobre el cap del cavaller mentre un filacteri indica el motiu del triomf: «non coronabitur nisi qui legitime certaverit» (2 Tim 2,5). Enfront del cavaller, un diagrama explica com els dons de l'Esperit Sant, representats per coloms, es contraposen als pecats capitals, representats per monstres (Evans1986).

Evidentment, aquest diagrama expressa de manera sintètica el combat cristià, és a dir, la lluita de cada fidel cristià contra si mateix per desterrar l'egoisme. Explica que la batalla quotidiana contra els enemics de l'ànima és l'única drecera segura per abastar la benaurança eterna, representada a la il·lustració per l'àngel que lliura el guardó al vencedor: la corona triomfal i les benaurances eternes.

Es pot llegir la rèplica verbal d'aquest discurs visual que acabem d'explicar al Communiloquium de Joan de Gal·les, que en parlar de la cavalleria, estableix quatre categories i n'anomena una com a cavalleria cristiana, la qual no té per funció la defensa dels enemics materials sinó dels espirituals:

Altra cavalleria hi ha qui és dita cavalleria cristiana [...] de la qual cavalleria diu Job ${ }^{2}$, VII capítol, que la vida de l'hom sobre la terra és cavalleria, la qual paraula spon sent Gregori, VIII libre de Les morals ${ }^{3}$, al començament, e aquí ell parla suficientment d'aquesta cavalleria e dels seus enemichs, contra los quals se ha a combatre tot feel cristià cavaller d'aquesta cavalleria, lo qual, si vol ésser leyal cavaller al rey celestial nostre senyor Déu, deu ésser cert, e avist, e ben adoctrinat, e exercitat, e virtuós e ferm de cor (Com. 1,9,7).

Al fragment anterior, Joan de Gal·les reclama que el cavaller cristià siga «virtuós». El programa de les quatre virtuts cardinals potser siga un dels manlleus més reeixits que la moral medieval va prendre dels savis de l'antigor. En efecte, des de la República de Plató i tot al llarg de l'època medieval, malgrat no canviar el nom de les virtuts, s'elaboraren doctrines constants respecte a la

2 Iob 7, 1 «Militia est vita hominis super terram et sicut dies mercennarii dies eius».

3 Gregori Magne, Moralium libri..., PL 75, 805 B: «Vita nostra, et militia et tentatio eodem sensu. Ipsa sibi tentatio est.-Hoc in loco translatione veteri nequaquam militia vita hominis, sed tentatio vocatur. Sed si utriusque verbi sensus aspicitur, diversum quidem est quod exterius resonat, sed unum eumdemque concorditer intellectum format.» 
interconnexió, jerarquia o relació amb altres virtuts annexes i els vicis que s'hi contraposen (Bejczy 2011).

Al llarg el segle XII, l'interés per les virtuts cardinals revifà. Alguns pensadors, com Pere Abelard o Joan de Salisbury, tornaren els ulls vers l'antiguitat clàssica per a reflexionar sobre les virtuts cardinals mentre que d'altres, com Bernat de Claravall, consideraren que les reflexions clàssiques estaven mancades de l'abast sobrenatural que hi afegia el pensament cristià. Aquestes postures posaven damunt la taula el vell debat cristià de la interacció entre naturalesa $\mathrm{i}$ gràcia que, a partir del 1160, tractaren de resoldre els teòlegs de París. ${ }^{4} \mathrm{Al}$ segle XIII, i com a consequiència de les elucubracions ètiques de la centúria anterior, l'estudi de les virtuts esdevingué un tema de cabdal importància en la discussió teològica que es veié reflectit en tractats d'educació de prínceps i en la praxis de confessors i postuladors de les causes de canonització $c f$. Vauchez (1991: 592).

De tots es sabut que malgrat les afinitats manifestades entre el pensament clàssic i el medieval, l'antropologia subjacent en el pensament moral medieval és completament diferent d'aquell de l'ètica clàssica perquè tota la moral cristiana pivota sobre la naturalesa caiguda de l'ésser humà i la necessitat de la gràcia per a restablir-la. ${ }^{5}$

\section{II.- SOBRE LA VIRTUT DE LA FORTALESA}

Després de la posada en circulació de les obres d'Aristòtil en versió llatina, aparegueren un llarg seguit d'obres sobre les virtuts cardinals entre les quals es troben Quaestiones disputatae de virtutibus cardinalibus (1272) de Tomàs d'Aquino (S. Th.) i el Breviloquium de virtutibus (c.1270) de Joan de Gal.les (Brev). ${ }^{6}$ Aquestes dues obres més el Communiloquium o Summa de Col-lacions

4 Bejczy (2011:71): «Adherents of all three positions defended their views notably in reference to the cardinal virtues. For Abelard, these virtues expressed what ancient and Christian morality had in common; for Bernard, the Christian character of the four virtues implied that they had no value in their classical conception; for the Parisian master, the place of the cardinal virtues in ancient as well as Christian morality indicated that notably these virtues existed on the level of nature as well as grace.»

5 En alguns Pares de l'Església sembla confondre's la fortalesa grega i la fortalesa cristiana. Sant Climent d'Alexandria, al segle III, i amb ell els pares grecs, identifiquen les concepcions estoiques de la fortalesa amb les concepcions bíbliques. El mateix succeeix entre els pares llatins. Però es tracta sobretot d'una qüestió de termes. Encara que adopten termes que en la filosofia grega responen a conceptes distints, en el fons es tracta d'una concepció diferent. Així, quan Climent d'Alexandria afirma que el cristià perfecte és impassible podria semblar que s'està referint a l'ideal estoic. Malgrat això, per a ell, la impassibilitat consisteix en el menyspreu de les coses creades i en l'esperança de viure un dia amb Crist, i és un do, gratuït per tant, de la gràcia (Gauthier 1962: 734-735).

6 Al llarg de la segona meitat d'aquesta centúria, aparegueren, entre d'altres, els següents tractats sobre les virtuts: De bono (c.1248) d'Albert el Magne; Quaestiones disputatae de virtutibus cardinalibus (1272) de Tomàs d'Aquino; De regimine principum (1250-1253) i Speculum virtutum (1300) d'Engelbert d'Admont; el Breviloquium de virtutibus (c.1270) de Joan de Gal-les; Tractatus de quatuor virtutibus cardinalibus (1295) d'Enric de Rimini; De regimine 
(Com) de l'esmentat frare gal-lés han estat triades com a marc conceptual per a l'aproximació al tractament de la virtut de la fortalesa en els poemes I, II i III de Pere March.

El fragment del Communiloquium citat anteriorment posa de relleu dues característiques molt convenients al cavaller cristià: que siga adoctrinat i ferm de cor. Per adoctrinat es pot entendre que tinga uns coneixements teòrics previs a l'actuació pràctica que reclama la fermesa de cor. És a dir, que sense saber la relació existent entre les coses és impossible emetre un judici que guie una actuació ferma. Per tant, les característiques esmentades apunten cap a les virtuts de la fortalesa i de la prudència, genetrix et auriga virtutum. La prudència és prèvia a qualsevol virtut i té necessitat de mitjà per a qualsevol acció virtuosa «car com tota virtut requira prudència, així com aquella sens la qual no pot ésser [...] aquell qui fortment se vol emparar d'alcuna cosa terrible e difícil fa mester que u faça ab seny e ab raó». (Eiximenis 1986: 223)

La lectura del Communiloquium de Joan de Gal-les brinda dues definicions de prudència, una positiva - «prudència, qui és saber ben ordenar les obres materials» (Com 1,10,8) — i una altra negativa — «és imprudència, quant orde covinent e manera no és servada en aquelles coses que hom studia» (Com 5,2,5). El mateix autor, al Breviloqui, utilitza el concepte de prudència establert per Ciceró: «Hon segons que diu Tul-li en la Rethòrica ${ }^{7}$, en lo seguon libre, la virtut de prudència és certa sciència de les coses bones e males» (Gal-les 1930: 72). ${ }^{8}$ Pel que fa a l'efecte de l'adoctrinament sobre la virtut, diu fra Joan al Communiloquium: «lo seu sermó deu ésser profitós e deu ésser proposat escalfadament e ardent, per tal que sien de major virtut a moure les virtuts de les gents» ${ }^{9}$ (Com prol).

Òbviament, la diferència fonamental entre els conceptes de la virtut de la fortalesa expressats en la Sagrada Escriptura i la filosofia clàssica grega rau en el caràcter teocèntric del primer. Per al cristianisme, la fortalesa és un do de Déu que ell atorga a qui, reconeixent la pròpia debilitat, l'invoca amb confiança. Pau de Tars conta en una de les seues epístoles com s'adreçà a Déu demanant-li que el deslliuràs de les temptacions que el turmentaven i va escol-

principum seu de quatuor virtutibus cardinalibus pro eruditione principum (1387) de Miquel de Praga; De regimine principum (c.1280) de Gil de Roma. Cf. Bejczy (2011: 135-153).

7 Cicero (1998: 2,160).

8 Repecte a la virtut de la prudència, Eiximenis, al capíol 566 Dotzè (1986: 223), diu que el príncep «deu ésser fort en les seues adversitats i [...] l'om qui vol hobrar ab fortalea deu proceir discretament; car com tota virtut requira prudència, així com aquella sens la qual no pot ésser [...] aquell qui fortment se vol emparar d'alcuna cosa terrible e difícil fa mester que u faça ab seny e ab raó; car si alcun se emparava de cosa a la qual ell no és bastant, lavors no obraria fortment, car fer-ho va contra raó e son obrar lavors no seria d'om fort, mas seria obra de audàcia orada [...] La fortalesa requer encara gran deliberació qui aver-la y pot, car en fets soptosos no y pot ésser; car lo fet bé del-liberat és fet pus discretament e pus voluntàriament que altre e aytant com és pus discretament fet e pus voluntària aytant és pus virtuós e pus fort.»

9 Al Breviloquium, el mateix frare també fa menció a l'adoctrinament: «Aptesa és prudència de adoctrinar los ignorants, e per tal que-11 home informe e adoctrine primerement si mateix e puys informe los altres, seguons que és scrit en la doctrina dels philòsofs» (Gal·les 1930: 87). 
tar com a resposta: «En tens prou amb la meua gràcia» (2 Cor 12, 9-10). ${ }^{10}$ D'ací, entre altres moltes fonts, es pot concloure que per a la doctrina catòlica la fortalesa és un do de l'Esperit Sant. ${ }^{11}$ Eiximenis, al Dotzé del cristià, també insisteix en l'oració confiada i perseverant per obtenir la fortalesa perquè Déu «se ofer a dar-la-us volenter si la li demanats amb instància o us apparellats a reebre-la, e.1 ne preguem ab devota oració e continuada» (Eiximenis 1986: 241). Una altra obra esmentada al recompte de béns elaborat a la mort de Pere March, la Doctrina pueril de Ramon Llull, en parlar dels dons de l'Esperit Sant explica el do de fortalesa (Llull 1972: 90 i 95):

Lo Sant Sperit, fill, dóna als hòmens fort coratge per lo qual vencen e apoderen lurs enemichs e los delits d'aquest món, qui són enemichs de la glòria de l'altre segle. Ab lo Sant Sperit és hom forts contra sa carn e contra aquest món e contra lo demoni, e sens ajuda del Sant Sperit null home no pot vensre neguna d'aquestes tres batalles.

\section{III.- EL BREVILOQUIUM DE JOAN DE GAL·LES}

Pere March morí a Balaguer el 7 de juliol del 1413. Entre els béns inventariats després del seu decés, aparegueren trenta-set volums. Amedé Pagés (1912) féu una descripció d'aquesta biblioteca i afirmà que les preferències reals del poeta estaven relacionades amb escriptors moralistes i polítics com per exemple Innocenci III, Matfré Ermengaud, Egidi Colonna, Ramon Llull, Joan de Gal·les... Els esmentats autors contribuïren a la formació de la seua obra de caràcter greu i moralitzador ( $c f$. Cabré en March 1993: 38 i ss.).

10 Eiximenis (1986: 240) al capíol 573 Dotzè: «Apar encara la dignitat d'aquesta virtut si attens a açò qui dit és; e declara-la per altra manera Orígines, sobre aquella paraula de Salamó: Mulierem fortem, quis inveniet? On diu axí: Si noble e valerós, si acabadament vols ésser bo e virtuós, discreta fortalea ages; car qui virtuosament és fort, totes les altres virtuts dins si matex exercita a fer cascuna sa obra ab vigor e no res tèbeament. Aquesta fa a l'hom menysprear tota cosa difícil e àrdua si contra virtut se mou. Aquesta fa lo cor axí fort que tot lo món no·l pot torbar sinó peccat. Aquesta leva la pena de l'hom a desijar e a cerquar solament coses altes e nobles e virutoses e li fa menysprear coses baxes e mesquines e qui no són de negun preu. Aquesta no sap mesquinejar, no lexa l'om contendre ne mentir, ne·l lexa oyr, veure, parlar, ne sentir sinó coses altes, nobles e de gran valor. Aquesta fa l'om virtuós. Aquesta procura a l'hom gran nom e fama, riquees e plaers, honor e reputació per tota creatura. Aquest no lexa l'om ésser trist ne buyt ne fals. Aquesta fa l'om amable a amics e a enemichs. Aquesta fa l'om provident a l'esdevenidor, ferm de present, perseverant en bé, inmoble es on bon propòsit, ferm en sa provisió. Aquesta és fonament de veritat. Aquesta fa l'om estar segur e sens paor, no.1 lexa a tots creure, fa.1 justament viure, no.1 lexa soferir minva e nengun quant en si és, no·l lexa consentir en nenguana nequícia e a la fi porta'l salv a paradís. E donchs, diu aquest doctor, per què tots no cerquats aquesta, pus leugerament se pot aver, e Déus se ofer a dar-la-us volenter si la li demanats amb instància o us apparellats a reebre-la? E·l ne preguem ab devota oració e continuada.»

11 Sobre la fortalesa es pot consultar: S. Th., II-II, qq. 123-140; Gauthier (1950), Pieper (1965), Congar (1974), Aranguren (2000), Fuentes (2001). 
Entre els autors inventariats a la mort del poeta, apareix Joan de Gal·les, franciscà del segle XIII, professor a Oxford i a París. Al segle XIV, dues obres d'aquest autor, ja citades, foren traduïdes al català: el Communiloquium i el Breviloquium de virtutibus antiquorum Principum et philosophorum. ${ }^{12}$

El Breviloquium és una compilació d'exempla de gestes dels antics i els dits dels filòsofs clàssics agrupats al voltant de les virtuts cardinals. El seu lector model és el príncep cristià i tots els exempla recollits han estat triats d'obres clàssiques o cristianes però sempre tenen per protagonistes a governants i savis de l'antigor perquè «los eximplis dels sants suficientment són demostrats en lo Flos sanctorum e en les històries de la Sancta Scripture» (Gal-les 1930: 24). Ara bé, tot i que les definicions de les virtuts han estat triades d'autors pagans i que els protagonistes dels exempla també ho són, a l'epíleg del Breviloquium, Joan de Gal-les explicita que les virtuts si no han sguort a Déu [...] «no deuen ésser jutjades virtuts sinó acabats vicis» (Gal-les 1930:154). A diferència dels clàssics que cercaven l'honor com a premi de la virtut (Ética a Nicòmac IV, c. 3, 7-10), per al franciscà, les virtuts cardinals han d'estar amarades per la caritat que és l'única virtut perdurable en la vida eterna, «car alí une e tota virtut és amar ço que veus, e sobirane beneuyrança és haver ço que ames» (Gal·les 1930: 154).

El Breviloqui, seguint Macrobi ${ }^{13}$, diu que «a la fortalesa se pertany levar lo coratge sobre tota pahor dells perills, ne timbre res sinó coses letges e vicioses, e sostenir forment les adversitats axí com les prosperitats». Continua la definició dient «Car fortalesa és desig de coses grans, menyspreu de perills petits e sosteniment de trebal per cosa profitosa, honorable e virtuosa, segons que diu lo Tul·li en lo terç capítoll de la sua Rethorica: Fortalesa és rebre lo càrrech e trebal dels perills primerement sabuts, coneguts e considerats». ${ }^{14}$

L'anterior definició clàssica en què la virtut cobra importància per ella mateixa contrasta amb l'apareguda al Communiloquium, on, seguint sant Gregori, la fortalesa queda convertida en una necessitat de mitjà per «haver loguer eternal»:

12 Al llarg dels segles (Swanson 1989) s'han atribuït moltes obres inadequadament a Joan de Gal-les, per exemple: Tractatus de poenis inferni, Legimus apud Eusebium, Postillae in Epistolas Pauli i De factis Mahumetis. Igualment algunes de les seues obres han estat atribuïdes a altres. Actualment la llista de les seues obres arriba a la vintena: Breviloquium de Virtutibus Antiquorum Principum et Philosophorum, Communiloquium sive Summa Collationum, Compendiloquium de vitis illustrium philosophorum et de dictis moralibus, Breviloquium de sapientia sive philosophia sanctorum, Legiloquium o Tractatus de decem preceptis, Moniloquium, Summa iustitiae o Tractatus de septem viciis, De poenitentia, Ars praedicandi, Ordinarium seu Alphabetum vitae religiosae, Expositio in evangelium Iohannis, Collationes in evangelium Iohannis, Collationes super Matthaeum, Expositio super orationem dominicam, Expositio regulae Ordinis Fratrum Minorum, Tractatus exemplorum, Postilla in Apocalypsim, Sermones.

13 [est] fortitudinis animum supra periculi metum agere nihilque nisi turpia timere, tolerare fortiter vel adversa vel prospera (Macrobius 1963: 38).

14 Pere March, com veurem més avant, defineix la fotalesa amb les mateixes paraules de Macrobi. L'endreça del poema Al punt c·om naix (I) demana a Déu cor e voler sforçat, / ques ab plaser prenda l'adversitat / e sens ergull lo be que breument passa (I 71-72). 
E sent Gregori, en lo VI de Els morals ${ }^{15}$ : «Fortalesa dels justs és vencre la carn e als propis desigs, contrastar el delitament de la present vida, apagar e amortar e amar asprea d'aquest món per haver loguer eternal, e menysprear ablaniments de prosperitat e sobrar temor de adversitats corporals» (Com. 3, 2, 4).

\section{IV.- LES VIRTUTS ANNEXES A LA FORTALESA}

Com ja ha quedat dit i seguint la doctrina catòlica, el món, el dimoni i la carn són els enemics de l'ànima els quals han de ser atacats o resistits, segons convinga, per la virtut de la fortalesa. Així ho explica Ramon Llull a la Doctrina pueril (Llull 1972: 167):

Fortitut és força de coratge qui esforça los poders de l'ànima spirituals. E fortitut és enfortiment d'ànima, per lo qual és vivificada força corporall. E fortitud és nobilitat e seguretat de coratge. Amable fill, si vols ésser fort contra la batalla de ta carn e del món e del diable, hajes fortitut en ton coratge, cor fortitut és tan noble virtut, que tota batallya vens e apodera; e en neguna cosa qui sia vençuda ne apoderada spiritualment, no està fortitut.

Tomàs d'Aquino, a la Summa Theologiae, en exposar la virtut de la fortalesa també parla de les virtuts annexes i dels vicis que s'hi contraposen. Explica que els vicis contraris a la fortalesa són: la covardia ${ }^{16}$, que defuig els sofriments necessaris per a aconseguir el bé ardu; la impavidesa ${ }^{17}$, que no evita els perills podent i tenint l'obligació de fer-ho; i la temeritat ${ }^{18}$, que menysprea l'opinió de la prudència per acarar el perill.

15 Gregori Magne, Moralium libri..., PL 75, 778 A.: «Justorum quippe fortitudo est carnem vincere, propriis voluntatibus contraire, delectationem vitae praesentis exstinguere, hujus mundi aspera pro aeternis praemiis amare, prosperitatis blandimenta contemnere, adversitatis metum in corde superare.»

16 S. Th., II'-IIae, q. 125 a. 2 co.: «Unde similiter inordinatus timor includitur in quolibet peccato, sicut avarus timet amissionem pecuniae, intemperatus amissionem voluptatis, et sic de aliis. Sed timor praecipuus est periculorum mortis, ut probatur in III Ethic. et ideo talis timoris inordinatio opponitur fortitudini, quae est circa pericula mortis. Et propter hoc antonomastice dicitur timiditas fortitudini opponi».

17 S. Th., II ${ }^{\mathrm{a}}$-IIae, q. 126 a. 2 co.: «Unde ad fortitudinem pertinet timor moderatus secundum rationem, ut scilicet homo timeat quod oportet, et quando oportet, et similiter de aliis. Hic autem modus rationis corrumpi potest, sicut per excessum, ita et per defectum. Unde sicut timiditas opponitur fortitudini per excessum timoris, inquantum scilicet homo timet quod non oportet, vel secundum quod non oportet; ita etiam impaviditas opponitur ei per defectum timoris, inquantum scilicet non timet aliquis quod oportet timere».

18 S. Th., II'-IIae, q. 127 a. 1co.: «Respondeo dicendum quod audacia, sicut supra dictum est, est passio quaedam. Passio autem quandoque quidem est moderata secundum rationem, quandoque autem caret modo rationis, vel per excessum vel per defectum; et secundum hoc est passio vitiosa. Sumuntur autem quandoque nomina passionum a superabundanti, sicut ira dicitur non quaecumque, sed superabundans, prout scilicet est vitiosa. Et hoc etiam modo audacia, per superabundantiam dicta, ponitur esse peccatum». 
La virtut de la fortalesa, per la seua naturalesa, no es pot dividir en virtuts específicament diferents sinó que posseeix virtuts annexes: la magnanimitat, la magnificència, la paciència i la perseverança. ${ }^{19} \mathrm{La}$ part dedicada a la fortalesa en el Breviloquium es divideix en quatre capítols que fan referència, precisament, a les virtuts annexes a la fortalesa: magnificència ${ }^{20}$, confiança ${ }^{21}$, paciència $^{22}$ i perseverança ${ }^{23}$. No parla, però, dels vicis oposats a cada una d'aquestes virtuts.

A la magnanimitat s'oposen: la presumpció, que consisteix a obstinar-se a realitzar alguna cosa que depassa les pròpies forces ${ }^{24}$; l'ambició, que és l'apetit desordenat d'honor ${ }^{25}$; la vanaglòria, que consisteix a desitjar una glòria vana, per buscar-la en coses fràgils i caduques que no són dignes de glòria; o quan es pretén rebre glòria per part dels homes, el judici dels quals és fal·lible 26 ; i la

19 S. Th., II'-IIae, q. 128 co.: «Fortitudini autem, secundum quod est specialis virtus, non possunt assignari partes subiectivae, eo quod non dividitur in multas virtutes specie differentes, quia est circa materiam valde specialem. Assignantur autem ei partes quasi integrales, et potentiales».

20 «Magnificència és una ample administració del coratge a fer coses grans e altes, segons que posa Tul·li en lo lo libre al·legat. Ytem, la dite magnificència és avorriment de subjugar-se a viltat e de ésser privat de llibertats. Ytem, sta la magnificència en haver tostemps veritat en la bocha e haver en les mans coses altes e magnificoses» (Gal-les 1930: 118).

21 «E la dite confiança és virtut per la quall lo coratge, havent en si confiança e certa sperança, se posa e·s col·loca en grans coses e honestes, segons diu Tul·li en lo primer libre de la sue Rethòrica» (Gal·les 1930: 123).

22 «La quall pasciència sta en sostenir gran e per lonch temps voluntàrie aflicció e tribulació per causa de honestat e de profit, la qual se mostre en les coses forts e diffícills. [...] En quatre coses sta: primerament en sostenir menyspreus e improperis en paraules; segonament, en sostenir longues penes en los corsos; tercement, en remetre les injúries; quartement, en moderar e temprar la disciplina en les correccions» (Gal-les 1930: 126).

23 «Perseverança és virtut constituyde e formade en rahó perpetual e durable habitació [...] La qual perseverança no·s spaordeix per manaces ne·s inclina per prometences» (Gal·les 1930: 142).

${ }_{24}$ S. Th., II ${ }^{\mathrm{a}}$-IIae, q. 130 a. 1 co. Hoc autem communiter in omnibus rebus naturalibus invenitur, quod quaelibet actio commensuratur virtuti agentis, nec aliquod agens naturale nititur ad agendum id quod excedit suam facultatem. Et ideo vitiosum est et peccatum, quasi contra ordinem naturalem existens, quod aliquis assumat ad agendum ea quae praeferuntur suae virtuti. Quod pertinet ad rationem praesumptionis, sicut et ipsum nomen manifestat. Unde manifestum est quod praesumptio est peccatum.

${ }_{25}$ S. Th., II ${ }^{\mathrm{a}}$-IIae, q. 131 a. 1 co. Tripliciter ergo appetitum honoris contingit esse inordinatum. Uno modo, per hoc quod aliquis appetit testimonium de excellentia quam non habet, quod est appetere honorem supra suam proportionem. Alio modo, per hoc quod honorem sibi cupit non referendo in Deum. Tertio modo, per hoc quod appetitus eius in ipso honore quiescit, non referens honorem ad utilitatem aliorum. Ambitio autem importat inordinatum appetitum honoris. Unde manifestum est quod ambitio semper est peccatum.

26 S. Th., II -IIae, q. 132 a. 1 co. Potest autem gloria dici vana, uno modo, ex parte rei de qua quis gloriam quaerit, puta cum quis quaerit gloriam de eo quod non est, vel de eo quod non est gloria dignum, sicut de aliqua re fragili et caduca. Alio modo, ex parte eius a quo quis gloriam quaerit, puta hominis, cuius iudicium non est certum. Tertio modo, ex parte ipsius qui gloriam appetit, qui videlicet appetitum gloriae suae non refert in debitum finem, puta ad honorem Dei vel proximi salutem. 
pusil-lanimitat que consisteix a no voler aspirar al ben proporcionat a la nostra capacitat ${ }^{27}$.

La magnificència és la virtut que regula l'amor als diners, de manera que aqueix amor no impedisca concebre i realitzar coses grans amb una finalitat noble ${ }^{28}$. S'oposen a la magnificència la sumptuositat ${ }^{29}$, que porta a fer grans despeses, però innecessàries i fora del que és prudent i raonable; i la parvificèn$\mathrm{cia}^{30}$, que consisteix a no gastar el necessari i raonable.

La paciència és part de la fortalesa. La funció de la fortalesa és suportar els mals més difícils de tolerar. En canvi, correspon a la paciència suportar tota classe de mals sense sumir-se en la tristesa ${ }^{31}$.

La perseverança és la virtut que permet persistir en la realització del bé fins al final, suportant, quant siga necessari, la duració en tots els actes de virtut. ${ }^{32} \mathrm{~A}$ la perseverança s'oposen la pertinàcia o tossuderia, que inclina a obstinar-se a no cedir quan seria raonable fer-ho; i la blanor o mol-lície, que inclina a desistir amb facilitat de l'exercici d'una virtut quan es presenten obstacles ${ }^{33}$.

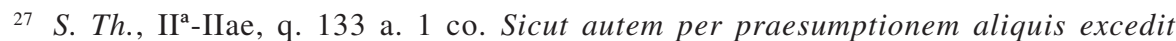
proportionem suae potentiae, dum nititur ad maiora quam possit; ita etiam pusillanimus deficit a proportione suae potentiae, dum recusat in id tendere quod est suae potentiae commensuratum. Et ideo, sicut praesumptio est peccatum, ita et pusillanimitas.

28 S. Th., II -IIae, q. 134 a. 3 co. Ad magnificentiam, sicut dictum est, pertinet intendere ad aliquod magnum opus faciendum. Ad hoc autem quod aliquod magnum opus convenienter fiat, requiruntur proportionati sumptus, non enim possunt magna opera fieri nisi cum magnis expensis. [...] Et ideo materia magnificentiae possunt dici et ipsi sumptus, quibus utitur magnificus ad opus magnum faciendum.

${ }_{29}$ S. Th., II ${ }^{\mathrm{a}}$-IIae, q. 135 a. 2 co. Respondeo dicendum quod parvo opponitur magnum. Parvum autem et magnum, ut dictum est, relative dicuntur. Sicut autem contingit sumptum esse parvum per comparationem ad opus, ita etiam contingit sumptum esse magnum in comparatione ad opus, ut scilicet excedat proportionem quae esse debet sumptus ad opus secundum regulam rationis. Unde manifestum est quod vitio parvificentiae, qua aliquis deficit a proportione debita expensarum ad opus, intendens minus expendere quam dignitas operis requirat, opponitur vitium quo aliquis dictam proportionem excedit, ut scilicet plus expendat quam sit operi proportionatum.

30 S. Th., II'-IIae, q. 135 a. 1 co. Ex hoc ergo dicitur aliquis parvificus quod intendit ad aliquid parvum faciendum. Parvum autem et magnum, secundum philosophum, in praedicamentis, relative dicuntur. Unde cum dicitur quod parvificus intendit aliquid parvum faciendum, facere parvum intelligendum est in comparatione ad genus operis quod facit. [...] Sic ergo patet quod parvificus deficit a proportione quae debet esse secundum rationem inter sumptum et opus. Defectus autem ab eo quod est secundum rationem, causat rationem vitii. Unde manifestum est quod parvificentia vitium est.

31 S. Th., II ${ }^{\mathrm{a}}$-IIae, q. 136 a. 4 ad 2. Ad patientiam autem pertinet ut propter huiusmodi tristitias, quantaecumque sint, homo non recedat a bono virtutis.

32 S. Th., II ${ }^{\mathrm{a}}$-IIae, q. 137 a. 3 co. Virtus perseverantiae proprie facit firmiter persistere hominem in bono contra difficultatem quae provenit ex ipsa diuturnitate actus, constantia autem facit firmiter persistere in bono contra difficultatem quae provenit ex quibuscumque aliis exterioribus impedimentis. Et ideo principalior pars fortitudinis est perseverantia quam constantia, quia difficultas quae est ex diuturnitate actus, est essentialior actui virtutis quam illa quae est ex exterioribus impedimentis.

33 S. Th., II -IIae, q. 138 a. 1 co. Respondeo dicendum quod, sicut supra dictum est, laus perseverantiae in hoc consistit quod aliquis non recedit a bono propter diuturnam tolerantiam 
V.- ELS POEMES «AL PUNT C'OM NAIX COMENSA DE MORIR» (I), «JO·M MARAVELH COM NO·S VE QUI HULHS HA» (II), «CEST FALÇ DE MON NO·L PRESI UN PUGES» (III) DE PERE MARCH

La Carta-Prohemio al condestable de Portugal (López de Mendoza 1980) ha passat per ser un dels primers exponents de la crítica literària hispana. El marqués de Santillana hi descriu succintament el pare d'Ausiàs March com $a$ valiente e honorable cavallero fizo assaz gentiles cosas e, entre las otras, escrivió proverbios de gran moralidad. La descripció realitzada per Íñigo López de Mendoza es convertí en el criteri de classificació de l'obra de Pere March seguit per Amedé Pagés (1912) i Romeu (1983) en les seues respectives edicions.

Cabré (March 1993), l'excel-lent edició del qual segueix el present treball, optà per uns altres criteris organitzatius atenent a tradició manuscrita, versificació, estil, temes i motius. Així establí un grup, al qual anomenà sàtires políticomorals, on situà els poemes: Al punt c'om naix comensa de morir (I), Jo.m maravelh com no.s ve qui hulhs ha (II), Cest falç de mon no.l presi un puges (III), Tots grans senyors qui be vol avenir (IV) y Cest qui ço fay d'on li deu seguir dan (V). Seguint encara temes i motius, Cabré dividí aquests sirventesos en dos grups: aquells que tracten el contemptu mundi (I-III) i aquells que tracten l'avís polític (IV-V) March (1993: 59 i ss.).

Als poemes del primer grup (I-III) establert per Cabré, Pere March critica vicis als quals contraposa la virtut de la fortalesa. Es tracta de tres poemes en què el poeta censura una sèrie de comportaments viciosos alguns dels quals han esdevingut arquetípics: el vell que pensa que és jove, el jove jactanciós, la perfídia del poder, el monjo orgullós, el curial llagoter, el governador cruel, avar i inepte, etc. Òbviament, tots aquests exempla ${ }^{34}$ presenten una finalitat argumentativa orientada a modificar l'actitud del receptor «car lonch camí és per los manaments, mas breu senda és e de gran efficàcia per los eximplis» (Com. 5, 2, 1).

Es tracta, ni més ni menys, de l'adoctrinament del cavaller cristià de què feia esment sant Gregori en Moralia in Job. Els poemes de March que formen aquest bloc desaproven una sèrie d'actituds negatives i que interpel-len el receptor perquè modere la «delectació de la carn, la cobejança del món, la honor transitòria del setgle» (Com. 7,1,2) ${ }^{35}$.

Tots tres poemes ofereixen una mateixa intenció: el desig de «far bons fayts e los mals avorrir» (III, 63). Potser siga per les directrius de la Sobregaya com-

\footnotetext{
difficilium et laboriosorum. Cui directe opponi videtur quod aliquis de facili recedat a bono propter aliqua difficilia, quae sustinere non potest. Et hoc pertinet ad rationem mollitiei, nam molle dicitur quod facile cedit tangenti. Non autem iudicatur aliquid molle ex hoc quod cedit fortiter impellenti, nam et parietes cedunt machinae percutienti.

${ }^{34}$ Gregori Magne, In Ezechielem Prophetam (PL 76, col. 1014): «Plus enim plerumque exempla quam ratiocinationis verba compungunt».

35 1Jn 2,16: «Quoniam omne, quod est in mundo, concupiscentia carnis et concupiscentia oculorum et iactantia divitiarum, non est ex Patre, sed ex mundo est».
} 
panyia dels set trobadors de Tholosa ${ }^{36}$, els poemes Al punt c'om naix comensa de morir (I), Jo.m maravelh com no.s ve qui hulhs ha (II), Cest falç de mon no.l presi un puges (III) presenten endreces religioses i poden ésser entesos com a una oració conseqüència de la meditació d'uns fets exemplars. ${ }^{37}$

Les tres composicions esmentades acaben demanant, a Déu o a sa Mare, la virtut de la fortalesa, les dues primeres de manera explícita — «pregui Dieu c'a luy plassa / donar me cor e voler sforçat» (I); «vostre Filh [...] me don gran fortelesa» (II) - i, al poema III, el poeta demana la intercesió de la Mare de Déu per poder abandonar tot comportament viciós. En definitiva, aquest poema també demana la virtut de la fortalesa perquè «si acabadament vols ésser bo e virtuós, discreta fortalea ages; car qui virtuosament és fort, totes les altres virtuts dins si matex exercita a fer cascuna sa obra ab vigor e no res tèbeament» (Dotzè 1986: 240).

El Communiloquium de Joan de Gal-les fou pensat com una eina perquè aquells predicadors que no tingueren llibres a l'abast o temps per poder preparar els seus sermons poguessen prendre materials d'aquesta pedrera d'al-luvió. Tot i que els primers destinataris d'aquesta obra foren els clergues, també la llegiren laics, tant nobles com burgesos, entre ells Pere March segons es desprén del seu inventari post mortem a què ja s'ha fet al-lusió (March 1993:38 i ss.). Joan de Gal-les agrupa temàticament les citacions i entre elles, molt de tard en tard, apareix la veu del frare que anima a l'amonestació.

I aquesta és precisament la intencionalitat de Pere March en els poemes I, II i III on sembla escoltar-se el ressò de la veu del gal-lés, quan en la part del llibre destinada a ben morir escriu:

Mas lo contrari és de molts als quals desmembren les dites coses virtuoses e miren o sguarden la voluntat o delectació de la carn, la cobejança del món, la honor transitòria del setgle, (...) donchs, deuen-se tots los hòmens amonestar que-s guarden de aytal desordenada e vana inquissició, e deuen-se amonestar que hajen memòria e regonexença de les coses altres pus profitoses dessús dites (Com. 7, 1,2).

${ }^{36}$ El record de la repressió de l'heretgia albigesa i el temor a la Inquisició eren tan vius a Tolosa i en tota la regió del Llenguadoc, que la primera cosa que s'exigia als concursants era l'ortodòxia religiosa. Només podien lloar Déu, la Verge i els sants o, a tot estirar, tractar temes segellats amb la moralitat més austera. L'única dona que podia ser objecte del seus homenatges era la Verge, i calia que els versos de la tornada s'adreçassen a ella o a Déu (Pagés 1990: 128).

37 Guigó el Cartoixà $(† 1118)$ al segon capítol Scala claustralium o Scala Paradisi explica la metodologia per aplegar a la contemplació. El sistema està dividit en quatre fases: lectio, meditatio, oratio i contemplatio. Són quatre graons interrelacionats basats en la lectio divina, és a dir, la lectura sistemàtica de la Sagrada Escriptura, quan sobre el fragment llegit s'estableixen les causes, efectes i finalitats s'aplega a la meditatio, que si esdevé petició es converteix en oratio (Guigues 1970: 84). 
Pere March vol amonestar posant la lent d'augment en l'actitud «desordenada e en la vana inquisió» d'alguns perquè pensen en realitzar obres pus profitoses. La intencionalitat imposa la tria del sirventés «per castiar cels que fan mal» ${ }^{38}$.

Segons el gal·lés, l'actitud desordenada segueix «la voluntat o delectació de la carn, la cobejança del món, la honor transitòria del setgle». Aquesta es l'actitud que pretén abandonar el poeta, amb l'ajut de la mare de Déu, i a què fan menció els darrers versos del poema III (71-72): «perque d'est mon yeu pugua derenclir / tot ço que vos desplagues si u fasia».

El poeta no vol deixar-se arrossegar per les tres concupiscències (1Jn 2,16) que estan a la base dels pecats capitals i que, a més del pronus peccati, tenen per aliats els tres enemics de l'ànima: li Cetan, la carn e.l mon (III, 18-19). Cadascun d'ells presenta una especialitat: «Cetan vol ergulh, ira, falcia; la carn, menjar e femnes e dormir; e·1 mon, tresaur e pompes e gaudir» (III, 21-23).

Al sotmetiment a les tres concupiscències, el poema contraposa la llibertat dels consells evangèlics: castedat front a la concupiscència de la carn: — «e celh caytiu qui peccat vol seguir» (III, 38) ${ }^{39}$ - veritable pobresa front a la concupiscència dels ulls — «e celh es richs qui domda son desir» ${ }^{40}$ - i obediència front a la supèrbia de la vida — «Reys es totz homs qui per dretxura.s guia» ${ }^{41}$.

El poeta adverteix que cal estar preparat per a l'estricte judici de Déu «que mils que nós sab quez obram tot dia» (III, 31-32). Dona les claus de la preparació: «Siam senyors, pus Dieus ho ha permes [...] que.l mon es fayt per al nostre coman e nos de Dieu» (9-12). Aquests versos aporten la idea del domini cristià sobre tota la creació expressat per sant Pau (1Cor 3,22-23), un domini jerarquitzat i, al mateix temps, controlat per «entendimen, rayso e franch talan» (III, 26) que condueix a l'observança dels manaments per a aconseguir «lo joy que.ns ha promès» $\left(\right.$ III, 28) ${ }^{42}$.

38 «Sirventes es dictatz que play / (...) tractans de mal dig general / per castiar cels que fan mal» (Anglade, 1919: II, 181).

39 Joan de Gal·les, al Communiloquium, pren paraules de les Epístoles de Sèneca i diu: «O tan grans senyors ha e.1 món qui són tenguts e ligats ab ligams de gran error, e aquells qui són bèsties e pechs tenen-los per benauyrats cor han gran senyoria e no guarden que són sostmeses a vicis» (Com 1, 3, 19).

40 El Communiloquium segueix Sèneca: «Per què diu aquí Sènequa: "Aquest hom servu és de cors, emperò per aventura és franch en l'ànima e, si és servu de cors, açò no li nou res. Mostra'm qui és aquell qui no sia servu: los uns servexen a luxúria, los altres a•varícia, los altres a·mbició, e tots han temor. E nenguna servitud no és pus vil que aquella qui és voluntària." Donques, com sia cosa possible que 1 senyor alcuna vegada sia servu d'aquestes passions damunt dites, e per aventura per contrari lo servu sia senyor d'aquelles, lo senyor no·s deu haver al servu ergullosament» (Com. 2,1,2).

41 A pròposit del veritable govern, Joan de Gal·les explica: «Donques, com ell regeix dreturerament, ell retén nom de rey e, quant pecca o erra, ell pert aquell nom. Rey seràs si dreturerament les obres fas, e si dreturerament no les fas, rey no seràs. Donchs, segons açò, aquell és rey e príncep verdaderament lo qual ha senyoria e govern sobre si matex e sobre sos desigs e sobre los desigs carnals» (Com. 1, 3, 19).

42 Pel que fa al domini de la creació per part de l'ésser humà, diu el Communiloquium: «Donques, los prínceps e.ls senyors no·s deuen tenir massa en alt e en car per senyoria, com 
Ésser al cim de de la creació exigeix un ús ordenat per la raó dels «que be n'useran» (III, 43). El jo poètic de Pere March adverteix que tant l'ús com l'abús de la creació tindrà les seues conseqüències. Lectura de 1'Apocalipsi ${ }^{43}$ in mente, recorda al lector la importància d'afanyar-se a fer el bé i evitar el mal ja «que.lls faytz nos seguiran, / e mals e bos», (III, 59-60) ${ }^{44}$. Exhorta «en far bons fayts e los mals avorrir» (III, 63). Aquest darrer vers explica l'essència de la virtut de la fortalesa que consisteix en obrar el bé i no, simplement, en superar les dificultats ${ }^{45}$.

El subjecte de la fortalesa és l'apetit irascible guiat per la raó. Ara bé, segons la doctrina catòlica, com a conseqüència del pecat original, l'apetit irascible pot actuar autònomament. Per tant, cal una disposició estable que el conduïsca segons els judicis de la raó. Evidentment, aquesta disposició estable és la fortalesa que és com «vestidura de la ànima de la qual vestidura naix asiduytat e continuació de totes bones obres» (Com. 1,1,8). Respecte al govern de l'apetit irascible per part de la raó diu Eiximenis al capítol 566 del Dotzé del Crestià (Eiximenis 1986: 223):

La fortalesa requer encara gran deliberació qui aver-la y pot, car en fets soptosos no y pot ésser; car lo fet bé del-liberat és fet pus discretament e pus voluntàriament que altre e aytant com és pus discretament fet e pus voluntària aytant és pus virtuós e pus fort.

Ha quedat dit que la virtut de la fortalesa té per subjecte l'apetit irascible i per finalitat remoure els impediments que venen de les passions del temor i la temeritat — «car virtut té en via migancera, entre poch e molt» $($ Com . 1,1,2) — perquè la voluntat seguisca els dictats de la raó que ha d'estar guiada per la

no sien senyors per natural condició, mes per demèrit de peccat. On diu aquí sent Agostí que·ls senyors servexen a aquells sobre los quals sembla que hajen senyoria; e no deuen senyorejar per copiditat de senyorejar, mes per ofici de donar consell, ni per ergull de senyorejar, mes per misericòrdia de provehir. Axí.u declara orde natural, e axí formà Déu l'hom, e dix-li que hagués senyoria sobre lo peix de la mar, e sobre les bèsties de la terra, e sobre los aucells del àer, axí com apar en lo primer capítol de Gènesi. E no volch que criatura qui no hagués rahó senyorejàs a l'hom, abans volch lo contrari, ço és, que l'hom, qui ha rahó e és fet ymatga de Déu, hagués senyoria sobre les criatures irracionals; e no dix que hom fos senyor d'hom mes de les bèsties. E per esta rahó los primers hòmens justs foren pastors de bestiar mes que reys d'hòmens, segons que appar en Gènesi, XLVII capítol, e açò per tal que Déus manifestàs als hòmens què requir l'orde de les criatures e què requir mèrit de peccats. Tot açò diu aquí sent Agostí» (Com. 2, 1, 2).

43 Ap 14,13. Feliços els qui des d'ara moren en el Senyor! Sí, diu l'Esperit, que reposin del seu esforç, perquè les seves obres els acompanyen.

44 La setena part del Communiloquium diu respecte a l'acumulació de bones obres: «Axí deuen fer tots los feels en aquesta defectible vida: ajustar les garberes dels mèrits que han guanyat en la vida spiritual, per tal que de aquestes sia verificada la paraula del psalmista on diu: "Mas los vivents vendran, ço és, a la glòria celestial, aportants falguades de bons mèrits ab gran alegria." Cor diu sanct Paul en Epístola dels Gal-lacians en lo derrer capítol: "Dementre havem temps obrem bones obres a tots" » (Com. 7, 1, 2).

45 S. Th. II ${ }^{\mathrm{a}}$-IIae, q. 123 a. 4. Ad virtutem fortitudinis pertinet ut voluntatem hominis tueatur ne retrahatur a bono rationis propter timorem mali corporalis. 
prudència. Forma part de la virtut de la prudència la cautela que indica el límit entre la virtut i el vici. Joan de Gal·les, al Breviloqui, ho explica de la següent manera (Gal·les 1930: 87):

Cautela és diferència entre virtuts e vicis, posant les virtuts devant los vicis. Car los vicis a veguades se dissimulen e apparexen virtuts, seguons que diu Sènecha en la XXIII epístola; e Sent Greguori en los Moralls, que molts vicis menten a vegades mostrant-se virtuts. Car la prodigalitat voll ésser vista liberalitat, la avarícia tenprance, la crueltat justícia. Per què, per fer diferència entre aquestes coses ha mester cautela; car, segons que diu Ciceró, no ha pus forts spies al món que són aqueles qui s'amaguen sots semblança de leyaltats.

El poeta no deixa de sorprendre's per l'actitud del temerari «qui faça gran aulesa / per folh plaser qui dura pauch moment» (II, 5-6); per la impavidesa de la ignorància culpable — «com no·s ve qui hulhs ha / e celh qui ou per que no vol entendre, / e qui no sap per que no vol apendre» (II, 1-3) — i per la covardia de «celh qui pot e sap com be no fa» (II, 4).

Considera boig a l'imprudent «qui no guarda on va» (II, 9); al sumptuós que essent pobre «trop vulha despendre», (II, 10) o qui «guasta.l sieu per viltats e peresa» (II, 32); al presumptuós «vessalh que 'b senyor vol contendra» (II, 11); i a l'inclinat a la vanaglòria «qui fa joventutz en velhesa» (II, 13).

El poeta critica el senyor parvificent: «qui trop streny la ma / al servidor a cuy la degra stendre» (II, 17-18); i pusil-lànim que es deixa influir per vicis de curials $\mathrm{i}$ «puga selh a cuy degra dexendra, / e cosselh cre d'om monsongier e va / e dona loch a lengua trop encesa / de mal perlar, diffeman e minten, / pausan discortz entremesclademen» (II, 19-23).

Els actes propis de la virtut de la fortalesa són atacar i resistir les dificultats per a viure i realitzar la veritat i el bé. Però l'actus principalior de la fortalesa no és atacar sinó resistir el temor. La resistència no s'ha d'entendre com a passivitat, sinó com a últim recurs de l'activitat i l'oposició al mal (S. Th. II-II, q. 123 a. 6).

El poeta recomana la senzillesa en l'expressió — «de xascus homs se tany que parle pla / clar, pauch e breu, ab dreyta rayso rendre» (II, 33-34) — defugint qualsevol manera d'expressar l'excel-lència pròpia, és a dir, la vanaglòria, defugint les manifestacions d'hipocresia - mentida, llagoteria — i de jactància difamació. ${ }^{46}$ Front a la mentida el poeta recomana parlar «ses verdat offendre, / e fayt dubtos que no·l jutge serta» (II, 35-36); evitar la difamació —e no diffam autruy ne dig'orresa, (II, 37) — la llagoteria — «ne lause molt hom qui.l sia

46 El Communiloquium compara els pecats de la llengua a ferides de sageta: «E dels falsos acusadors és vera la paraula que diu Jeremies, capítol VIIII, qui diu que ells han encesa lur lengua e han-ne fet arch de monçónegua e no de veritat. E la lur lengua és axí com la sageta nafrant, cor, així com la sageta nafra tost e soptosament e com hom no se'n sospita, axí la lengua del fals acusador sovent nafra los innocents en loch e en temps que no s'i són pensants. E aytal arch és malayit, cor d'ell hixen sagetes de falsa acusació e gita-les luny lla hon són aquells qui falsament accusa» (Com. 1, 5, 6). 
present», (II, 38) — i la jactància «ne sé ne fill ne son eretamen, / ne sa muller no lou de gentilesa». (II, 39-40) ${ }^{47}$ Els vicis que presenta Pere March indiquen una manca de resistència per a afrontar la veritat i son, en molts casos, armes al servei de l'ambició molt emprades pels curials ${ }^{48}$.

Pere March no mostra sorpresa pels comportaments exemplars de les set filles de la vanaglòria. ${ }^{49}$ Confronta la virtut de la paciència amb la hipocresia ${ }^{50}$ de l'ambiciós — «qu'age us d'elacra» ${ }^{51}$ (II, 41) — amb l'abús de poder — «de senyor qu'a tort vulha.l meu pendre» (II, 42) $)^{52}$ — amb la desobediència — de

47 Pel que fa al governant que es complau escoltant llagoteries diu el Communiloquium: «E diu lo Savi, Proverbiorum, XXVIIII capítol, que aquell qui volenter ou paraula de monçónegua haurà a tots los ministres malvats e cruels, cor per tal que ells sien plaents al senyor, es studien e enguinyen com poran despullar los pobres e per ells és loat lo peccador en los desigs de la sua ànima» (Com. 1, 8, 6).

48 Respecte als vicis dels curials, diu Joan de Gal-les al Communiloquium: «Tots los damunt nomenats són curials [...] e són alcuns peccats comuns a tots aquests en los quals solen pecar més que en altres [...] Lo primer dels quals és cobejosa ambició de possehir dignitats e honors. [...] Lo segon vici comú als curials és engan e monçónega, lausengeria o lagoteria, per la qual volen plaure als majors, per tal que aconseguesquen dignitat e honors, e als altres, per tal que ells sien favorables e que ls loen e diguen bé» (Com. 1,8,1-2).

49 S. Th. II-II, q. 132, a. 5: «Respondeo dicendum quod, sicut supra dictum est, illa vitia quae de se nata sunt ordinari ad finem alicuius vitii capitalis, dicuntur filiae eius. Finis autem inanis gloriae est manifestatio propriae excellentiae, ut ex supra dictis patet. Ad quod potest homo tendere dupliciter. Uno modo, directe, sive per verba, et sic est iactantia; sive per facta, et sic, si sint vera, habentia aliquam admirationem, est praesumptio novitatum, quas homines solent magis admirari; si autem per ficta sit, sic est hypocrisis. Alio autem modo nititur aliquis manifestare suam excellentiam indirecte, ostendendo se non esse alio minorem. Et hoc quadrupliciter. Primo quidem, quantum ad intellectum, et sic est pertinacia, per quam homo nimis innititur suae sententiae, nolens credere sententiae meliori. Secundo, quantum ad voluntatem, et sic est discordia, dum non vult a propria voluntate discedere ut aliis concordet. Tertio, quantum ad locutionem, et sic est contentio, dum aliquis verbis clamose contra alium litigat. Quarto, quantum ad factum, et sic est inobedientia, dum scilicet aliquis non vult exequi superioris praeceptum».

50 En un manual com el Communiloquium, no podia mancar l'amonestació a la unitat entre la vida i la prèdica del predicador: «Donchs, aquell qui la vol aprofitar en los seus hoydors visqua virtuosament en guisa que.ls informe. E de açò parla assats polidament Sènequa, en la VII Epistola, lla hon diu que los hòmens més crehen als huylls que no a les orelles. Car lonch camí és per los manaments, mas breu senda és e de gran efficàcia per los eximplis» (Com. 5, 2, 1).

51 Respecte al valor emblemàtic de l'escorpí diu Joan de Gal·les al Communiloquium: «E verament los lagoters són enganadors, e deceptors verdaders e enemichs, cor diu sent Jerònim, en la Epistola LXXXVIII, que·l lagoter blan e suau és enemich mortal. Aquests són semblants a escurpís qui ab la cara toquen mollament e suau e ab la coha punjen e envirinen. E d'açò parla Ezachiel, capítol III, e diu: “Tu habites ab scurpís.” E diu aquí sent Gregori, libre I, omelia VIIII, que.l lagoter és scurpí qui va palpant, mes ab la coha de fer, e és abella qui porta mel en la bocha e agulló en la coha. On los lagoters són semblants als preveres infernals, cor [ellas]ell dien paraules plasents e axí comencen quaix que vullen dir les vespres dels morts qui comença per Placebo, qui diu: "Yo seré plaent", mes a la fi ells soterren hom en pecats» (Com. 1, 8, 2).

52 Segons el Communiloquium, la diferència entre príncep i tirà rau en l'observació de les lleis: «Tot príncep, emperò, jatsesia que ell sia legudament instituhit, se deu guardar que no faça obres de tiran, axí com és que no faça opressió ni tort al poble, ni faça contra la lig dreturera, ni.ls agreuge de aquestes ni de talles, ni de forces, ni de trahits injustament; ni·ls tolga ço del lur, ni·ls 
«servidor altiu ab niciesa» (II, 45) — amb la pertinàcia — «ne metge folh ne pratich ne scien»(II,46); discòrdia d'advocat «qui tot plet vol empendre» $(\mathrm{II}, 43)$ — amb la contesa — «ne de vassalh qui renya com a ca» (II,44) — i amb la jactància «ne gran stat no vulhas ab pobresa» (II,48).

Finalment, Pere March recorda la mort i el judici de Déu e «si 'n peccat mortal es l'arma presa, / lo foch d'infern es son aleujamen» (II, 53-54); en canvi el guardó està reservat per a «celhs qui deçay fan de virtutz empresa» (II, $56) .53$

En opinió de Joan de Gal·les, l'exercici de la virtut de la fortalesa recondueix l'ésser humà cap a la seua veritable essència: «aquells són hòmens verdaders qui vencen lurs voluntats desordenades e treballen en obres virtuoses ordenadament, e regexen les virtuts jusanes ordenadament, e los desigs carnals» (Com. $3,1,1)$.

A l'endreça del poema Al punt c'om naix comensa de morir (I), Pere March demana a Déu la virtut de la fortalesa — «cor e voler sforçat» (I, 70) - que defineix seguint Macrobi: «ques ab plaser prenda l'adversitat / e sens ergull lo be que breument passa» (I, 71-72). ${ }^{54}$ És a dir, la resistència front a les circumstàncies vitals perquè «l'estat d'om qui tot jorn se cambia, / que.l rich es baix e.l baix pren manentia, / e.l fort es flach e.1 flach sab enfortir» (I, 42-44) ${ }^{55}$

Recorda que la vida és un camí cap a la mort «al punt c'om naix comensa de morir, / e morin creix, e crexen mor tot dia» (I, 1-2). ${ }^{56}$ Aquesta realitat indefugible és obviada per la presumpció del foll hom «que, remiran sa carn bella e

do aflicció ni treball occupant aquell en obres no degudes, ni·ls leix malmenar a altre, ni soffira que.ls oficials ni·ls prebosts ni.ls batles los facen sobergueries, e axí de les altres coses semblants. Cor diu sent Agostí, libre II de La ciutat de Déu, capítol XX, que rey injust tiran és» (Com. 1, 3, 20).

53 La setena part del Communiloquium, un tractat de ben morir, recomana la contínua remembrança del judici particular: «E a pensar e cogitar la mort en la manera dessús dita són stats tots los hòmens morts, segons que és recomptat en lo libre Ecclesiàstich, en lo XXXVIII capítol, hon se lig: "Axí remembre't de les coses derreres e no les vulles oblidar." E segueix-se "Remembre't del meu juhí, cor axí serà lo teu. A mi jutgaren hir e a tu huy." E per tal com les delectacions de la carn e los plaers del món apaguen l'hom que ell no puxa pensar la sua mort, per tal diu lo Savi, en lo Ecclesiastés, en lo VII capítol: "Millor cosa és anar a la casa del plor que a la casa del convit, cor en la casa del plor és amonestada la fi de totes coses"» (Com. 7, 1, 4).

54 Seguint Macrobi, defineix dient «A la fortalesa se pertany levar lo coratge sobre tota pahor dells perills, ne timbre res sinó coses letges e vicioses, e sostenir forment les adversitats axí com les prosperitats» (Gal-les 1930: 118).

55 Joan de Gal·les recorda la roda de la fortuna i la presencia continua de la mort: «Donchs, nengú no confiu en la virtut de la sua edat, ne en la força de la sua virtut, ne en la sanitat del cors, ni en la prosperitat e benahuyrança mundanal, car la mort no perdona a nengú e axí egualment moren los jóvens com los vells, axí los forts com los flachs, axí lo richs com lo pobres, axí los vassals com los senyors; a tots los hòmens és egual. E per tal diu sanct Johan en lo Apochalipsi: "Yo viu los morts grans e pochs stants en la presència de la cadira divina"» (Com. 7, 1, 3).

56 El Communiloquium equipara la vida a la mort: «Aquesta és mort dels vivents e és vida dels morients, segons que diu sant Augustí, en lo IIII libre de les Confessions» (Com. 7, 1, 1). 
grassa, / e.1 front polit e lo cors ben tallat, / ha tot lo cor e lo sen aplicat / als fayts del mon, que per null temps no·s lassa» (I,20-24).

El poema també critica la pertinàcia del «vell poyrit — qui jats en la gran bassa / de fanch pudent, tu.t bolques en peccat» ${ }^{57}$ (I, 37-38) - que dedicat a la maledicència ${ }^{58}$ i a la presumpció no fa cas de la malaltia, «missatge cert es que la mort t'envia» (I, 35); i viu com un parvificent — «la ma trop scassa» (I, 40)— i un hipòcrita — «ab lo cor fals» $(\mathrm{I}, 40)^{59}$.

Pere March fustiga la presumpció del vell mesquí que no pensa en la sobtadesa de la mort sinó que «fay leho de son gat / e pensa pauch en la mort qui.l menassa» (I, 47-48); la vanaglòria del regidor «qu'es fer e mal si u pot aconseguir» (I, 51-52); la humilitat hipòcrita del monjo de Grassa «qu'es ergullos quant ha gran dignitat» (I, 53-54); en les basques de la mort, el Sant Pare lamenta la perfidia del poder «Er fos eu un bover stat, / c'onor d'est mon a peccat embarassa!» ${ }^{60}(\mathrm{I}, 65-68)$; la insensibilitat del batle «qu'es fer e mal si u pot aconseguir» (I, 52); i la pusil-lanimitat del governador inepte «ffora millor a porquer de Terrassa» $(\mathrm{I}, 56)$.

Com a virtut contrària al vici de la vanaglòria — «Dieu a son vol convertir» (I, 60)—, recomana la virtut de la obediència, submissió, a Déu — «tot son voler a Dieu leixar deuria» ${ }^{61}(\mathrm{I}, 59)$ — com a condició de la verdadera alegria.

57 Hug de San Víctor identifica la luxúria amb el fang: «Ítem, diu aquí matex que la ànima racional quant és en la sua bona sanitat és axí com a vexell ferm e sancer, los quals vicis, axí com dit és, destruen e la retenen viciada e corrumpuda, cor per supèrbia ella és inflada, per enveja és secha, per ira és clara, per accídia trenqua, per avarícia se scampa, per gola és enmetzinada de túxech, per luxúria és calcigada e torna en loth e en fanga» (Com. 3, 5, 1).

58 El Communiloquium adverteix sobre el perill dels pecats de llengua i de pensament en la senectut: «Ítem, diu aquí matex que guardar-se deu hom de dos partides poques del cors, les quals per bé que lo cors envellesqua jamés no envellexen e tiren l'home a peccat, ço és, a saber, lo cor e la lengua, cor lo cor no cessa de atrobar novelles cogitacions e la lengua parla ço que lo cor ha pensat e cogitat» (Com. 3, 2, 6).

59 Respecte al sennex amans diu el Communiloquium: "Ítem, diu aquí que ell s'esforçà de ben viure abans de la sua senectut per tal que visqués bé en la senectut per tal que morís bé, cor aquell qui no és aytal és infant de C anys, qui vol dir infant en les sues costumes, del qual és scrit en Ysaya, en lo derrer capítol: "Infant de C anys morrà.” La qual paraula spon sent Gregori, en lo XVII libre de Els morals, e diu que lo pus leig del món es hom vell qui comença viure. Cor diu Sènecha, en la Epistola XIIII, que.ls vells se deuen studiar de gitar de si tots los acostumats delits desordenats e que.s pens continuadament en les culpes e en los defalliments que ha comeses en temps passat» (Com. 3, 2, 6).

60 La perfídia del poder és tractada en molt punts del Communiloquium, en la part dedicada a ben morir diu: «A aquesta consideració se deuen amonestar tots los hòmens, per tal que nengú no s'infle per les dignitats temporals e que no confiu en la benauyrança del setgle, mas que hajem cascuns memòria de la mort davant los huylls del seu cor axí com si fos hun spill en la qual deu considerar la sua fragilitat e dafalliment, e com en la mort són tolts los béns temporals, e com la mort és molt cruel e mala, car, com l'hom se pren sguart de aquestes consideracions, és retragut o retornat atràs de la inclinació de peccat e de la ambició de les honors mundanals e de les dignitats» (Com. 7, 1, 4).

61 Sobre l'acepcació de les circumstàncies vitals, diu el Communiloquium seguint les Epistoles de sant Gregori: «En esta vida no ha res stable e no mudable, mes són axí com a 
Aconsella viure la paciència com a virtut annexa de la fortalesa a qui correspon tant resistir les adversitats com allunyar-se de l'atracció de les tres concupiscèn$\operatorname{cies}^{62}$.

\section{VI.- CONCLUSIONS}

La lectura conjunta i complementària dels tres primers poemes de Pere March ofereix un programa ascètic basat en l'exercici de la virtut de la fortalesa. Tant el to de les endreces com el contingut general aproximen els tres poemes a les tècniques emprades en la homilètica medieval. Ara bé, mentre els predicadors utilitzaven els exempla per suavitzar l'eixutesa del discurs doctrinal, Pere March presenta una concatenació de comportaments arquetípics els quals blasma amb intenció catequètica.

S'ha pogut comprovar com els exempla adduïts no estan presos a l'atzar, ben al contrari, cadascun d'ells representa un vici oposat no solament a la virtut de la fortalesa sinó també a les seues virtuts annexes. A més de les set filles de la vanaglòria de què parla Tomàs d'Aquino, seguint les Morals de sant Gregori, tot al llarg dels tres poemes s'ha fet menció de huit vicis: presumpció, ambició, vanaglòria, pusil-lanimitat, parvificència, sumptuositat, insensibilitat i pertinàcia. Aquests vicis s'oposen a les quatre virtuts annexes: a la magnanimitat presumpció, ambició, vanaglòria, pusil-lanimitat —, a la magnificència — parvificència, sumptuositat—, a la paciència —insensibilitat o duresa de cor- i a la perseverança - pertinàcia-.

Darrere d'aquest repertori exhaustiu, sembla haver-hi un canemàs, possiblement, producte de les lectures doctrinals que es poden deduir de la biblioteca de Pere March. Amb alguns dels títols apareguts a l'inventari de llibres elaborat a la mort del poeta, s'ha pogut contextualitzar la lectura dels poemes estudiats.

En el present treball, s'han anotat a peu de pàgina les nombroses coincidències temàtiques entre el Communiloquium o Summa de Col-lacions de Joan de Gales i els versos de March. Tot i que en molts casos es tracta de punts comuns en aquest tipus de literatura, els paral-lelismes assenyalats entre ambdues obres semblen molt significatius, atés que l'obra del franciscà fou ressenyada a l'inventari realitzat a la mort del poeta.

viandant qui adés va per pla adés per muntanya, adés és alt adés és baix, adés puja adés devalla. E açò no és senyal de la ira de Déu, ans és senyal de la sua gràcia, per la qual aprén que nós devem conservar los seus dons, aytant pus verdaderament com los servam aytant pus humilment» (Com. $3,7,1)$.

62 «Los hòmens qui viuen en prosperitat e en benança deuen ésser amonestat que no·s gloriegen vanament de la lur benanaça, e aquells qui són en adversitat que no·s spaventen ne·s desesperen en lur treball, cor aquells qui han bona ventura en béns temporals segons lur voluntat no·s deuen ergullar, ni posar deuen lur fiança presumptuosament en aquells béns, ni deuen menysprear aquells qui sostenen tribulacions, e deuen-se pensar contínuament lo sobtós mudament de la ventura d'aquest món» (Com. 3, 7, 1). 


\section{BIBLIOGRAFIA}

Anglade, J. (1919) Leys d'amors. Manuscrit de l'Academie des Jeux Floraux, Bibliothèque Méridionale, Toulouse-Paris, Privat-Picard [reimpressió facsimilar de 1971, New York-London, Johnson Reprint Corporation].

Aranguren Echevarría, J. (2000) Resistir en el bien, razones de la virtud de la fortaleza en Santo Tomás de Aquino, Pamplona, Eunsa.

Bejczy, I. (2011) The Cardinal Virtues in the Middle Ages. A Study in Moral Thought from the Fourth to the Fourteenth Century, Leiden, Brill.

Bejczy, I. + C. Nederman (ed) (2007) Princely virtues in the Middle Ages, 1200-1500, Turnhout, Brepols.

Beltran, E. (1983) «Christine de Pizan, Jacques Legrand et le "Communiloquium" de Jean de Galles» Romania 104, pp. 208-28.

Bloomfield, M. W. (1955) «Preliminary list of íncipits of Latin works on the virtues and vices». Traditio 11, pp. 259-379.

Cicero (1998) De inventione ed. Theodor Nuslein, Leipzig, Teubner.

Com.: Veg. Gal·les (1997).

Congar, Y.M. (1974) Le traité de la forcé dans la «Somme Théologique» de s. Thomas d'Aquin, Angelicum 51 pp. 331-348.

Corpus Thomisticum, www.corpusthomisticum.org

Diem, A. (2009) «A classicising friar at work. John of Wales Breviloquium de virtutibus», Christian Humanism. Essays in Honour of Arjo Vanderjagt. Studies in Medieval and Reformation Traditions. Leiden, Brill.

Eiximenis, F. (1986) Dotzè llibre del Crestià. II.1, a cura de Curt Wittlin... [et al.] Girona, Col·legi Universitari de Girona-Diputació de Girona.

Evans, M. (1982) «Fragment of Peraldus's Summa of Vice, Harleian MS 3244» Journal of the Warburg and Courtauld Institutes 45, pp. 14-68.

Fuentes Mendiola, A. (2001) La fortaleza de los débiles: con el poder del espíritu, Bilbao, Desclée de Brouwer.

Gal·les, Joan de (1930) Breviloqui, a cura de Norbert d'Ordal, Barcelona, Barcino.

Gal·les, Joan de (1997) Edició crítica i estudi de la Summa de col-lacions de Joan de Gal·les, a cura de Lluís Ramon i Ferrer, València, Universitat de València

Gauthier, A. (1950) Magnanimité. L'idéal de la grandeur dans la philosophie païenne et dans la théologie chrétienne, París, J. Vrin.

Gregori Magne (1862) Moralium libri sive expositio in librum B. Job en: J.-P. Migne (ed.), Patrologia latina, París, vol. LXXV. 
Gregori Magne (1876) Homilliae XL in Ezechielem en: J.-P. Migne (ed.), Patrologia latina, París, vol. LXXVI.

Guigues, le Chartreux, (1970) Lettre sur la vie contemplative (l'échelle des moines). Douze méditations, ed. Edmund Colledge i James Walsh, Paris, Éditions du Cerf.

Hauf, A. (1990) D'Eiximenis a Sor Isabel de Villena: aportació a l'estudi de la nostra cultura medieval, Barcelona, Institut de Filologia Valenciana/Publicacions de l'Abadia de Montserrat.

Kempshall, M. (1999) The common good in late medieval political thought, Oxford, Clarendon Press-Oxford University Press.

López de Mendoza, Í. (1980) «Comienza el prohemio e carta quel marqués de Santillana envió al condestable de Portugal con las obras suyas», Obras Completas, edición de Manuel Duran, Madrid, Castalia.

Llull, R. (1972) Doctrina pueril. Barcelona, Editorial Barcino.

Lottin, Odon (1947-1960) Psychologie et morale aux XIIe et XIIIe siècles, Louvain, Abbaye du Mont César.

Macrobius (1963) Commentarii in Somnium Scipionis I, Leipzig, Teubner.

March, P. (1993) Obra completa, a cura de Lluís Cabré, Barcelona, Barcino.

Pagès, A. (1990) Ausiàs March i els seus predecessors, València, Institució Alfons el Magnànim.

Paz y Melia, A. (1901), «Noticias para la vida de Ausias March», Revista de Archivos, Bibliotecas y Museos 1, pp. 369-374.

Peraldus, Guilelmus, Summa de virtutibus et vitiis, British Library, Harleian MS 3244.

Pieper, J. A. (1965). The Four Cardinal Virtues, Prudence, Justice, Fortitude, Temperance. New York, Harcourt, Brace \& World.

Romeu, J. (1983) «Pere March, "Al punt c·om naix comença de morir"», Estudis de Llengua i Literatura Catalanes VI, Miscel-lània Pere Bohigas, 3 (Montserrat, Abadia de Montserrat, 1983) pp. 85-119.

S. Th.: Summa theologica, $c f$. Corpus tomisticum.

Swanson, J. (1989) John of Wales. A Study of the Works an Ideas of a ThirteenthCentury Friar. Cambridge, University Press.

Tubach, F. (1981) Index exemplorum: a handbook of medieval religious tales. Helsinki, Suomalainen Tiedeakatemia.

Vauchez, André, (1991) «Saints admirables et saints imitables: les fonctions de l'hagiographie ont-elles changé aux derniers siècles du Moyen Âge?», Les fonctions des saints dans le monde occidental (IIIe-XIIIe siècle), Roma, Publications de l'École française de Rome pp. 161-172. 